\title{
Hospitalized children continue to report undertreated and preventable pain
}

\author{
Kathryn A Birnie BA(Hons) ${ }^{1,2}$, Christine T Chambers PhD ${ }^{1,2,3}$, Conrad V Fernandez $\mathrm{MD}^{2,3}$; Paula A Forgeron PhD ${ }^{4}$, \\ Margot A Latimer PhD ${ }^{2,5}$; Patrick J McGrath PhD ${ }^{1,2,3,6}$, Elizabeth A Cummings MD ${ }^{2,3}$, G Allen Finley $\mathrm{MD}^{1,2,7}$
}

\begin{abstract}
KA Birnie, CT Chambers, CV Fernandez, et al. Hospitalized children continue to report undertreated and preventable pain. Pain Res Manag 2014;19(4):198-204.
\end{abstract}

BACKGROUND: Published reports of substantial rates of moderate to severe pediatric inpatient pain tend to overlook lower-intensity pain that may be clinically significant.

OBJECTIVE: To document the prevalence of clinically significant pain in pediatric inpatients by considering the pain threshold at which each child desires intervention, and to assess sources of pain, pain assessment and intervention, and relationships among demographic and medical variables to reported pain.

METHODS: Inpatients or their parents on four hospital units during four nonconsecutive days were eligible for inclusion. Interviews (76 parents; 31 patients) captured experiences of 107 inpatients (three weeks to 18 years of age) including current, worst and usual pain, pain treatment thresholds, sources of pain and help received during the previous $24 \mathrm{~h}$. A chart review provided data regarding demographic and medical variables, and pain assessment and management.

RESULTS: In total, $94 \%$ of patients experienced pain. The prevalence of clinically significant pain was $8 \%$ (current), 62\% (worst) and 24\% (usual). Current and worst pain was primarily procedural, and usual pain was primarily disease related. On average, patients had 4.03 documented pain assessments over $24 \mathrm{~h}$. Caregiver responses (eg, reassurance) and nonpharmacological interventions were frequently reported $(>90 \%)$ but infrequently documented $(<50 \%)$; $66 \%$ of patients received pharmacological interventions. Younger patients received fewer pain assessments and opioids. Patients with clinically significant usual pain were more likely to have undergone surgery, and receive more pain assessments and interventions. CONCLUSIONS: While recent studies suggest reduced pain in pediatric inpatients, the present findings reveal a continued high frequency of undertreated pain. High rates of procedural pain are preventable and should be targeted given the underutilization of pain management strategies.

Key Words: Epidemiology; Hospital; Pain management; Pediatric pain; Pediatrics

Studies from the 1990s revealed that as many as three-quarters of $\checkmark$ pediatric inpatients report moderate to severe pain (1-3). More recent studies continue to report high rates of moderate to severe pain among hospitalized children (21\% to $64 \%$ ) (4-9). Although some improvements are noted following targeted pain knowledge translation initiatives (10), research involving eight pediatric hospitals in Canada revealed the continued regular occurrence of painful procedures with inadequate pain assessment and pain management $(11,12)$. Overall, these studies reach the disconcerting conclusion that a large number of pediatric inpatients experience undertreated pain despite many advances in effective pain assessment and treatment $(13,14)$. Despite providing valuable information regarding pain assessment and management, recent studies such as these, based exclusively on inpatient medical chart review, are limited by the absence of patient report (5,10-12). Furthermore, previous research has not considered

\section{Les enfants hospitalisés continuent de signaler des douleurs non traitées et évitables}

HISTORIQUE : Les rapports publiés de taux importants de douleur modérée à grave chez les patients hospitalisés en pédiatrie ont tendance à sous-estimer la douleur de faible intensité qui peut être significative sur le plan clinique.

OBJECTIF : Étayer la prévalence de la douleur importante sur le plan clinique chez les patients hospitalisés en pédiatrie en évaluant le seuil de douleur auquel chaque enfant désire une intervention et évaluer les sources de douleur, d'évaluation de la douleur et d'intervention ainsi que le lien entre les variables démographiques et médicales et la douleur déclarée.

MÉTHODOLOGIE : Les patients hospitalisés ou leurs parents provenant de quatre unités hospitalières pendant quatre jours non consécutifs étaient admissibles à l'étude. Les entrevues (76 parents; 31 patients) ont saisi les expériences de 107 patients hospitalisés (de trois semaines à 18 ans), y compris la douleur courante, pire et habituelle, les seuils de traitement de la douleur, les sources de douleur et l'aide reçue pendant les 24 heures précédentes. Une analyse des dossiers a permis d'obtenir des données sur les variables démographiques et médicales, l'évaluation et la gestion de la douleur.

RÉSULTATS : Au total, $94 \%$ des patients ont ressenti des douleurs. La prévalence de douleur importante sur le plan clinique s'élevait à $8 \%$ (courante), $62 \%$ (pire) et $24 \%$ (habituelle). La douleur courante et pire était d'abord liée aux interventions, et la douleur habituelle était d'abord liée à la maladie. En moyenne, les patients présentaient des évaluations de douleur consignée de 4,03 sur 24 heures. Les mesures des personnes qui s'occupent d'eux (p. ex., les paroles rassurantes) et les interventions non pharmacologiques étaient souvent signalées (plus de $90 \%$ ), mais peu consignées (moins de $50 \%$ ); $66 \%$ des patients ont reçu des interventions pharmacologiques. Les plus jeunes patients ont reçu moins d'évaluations de la douleur et d'opioïdes. Les patients ayant une douleur habituelle importante sur le plan clinique étaient plus susceptibles d'avoir subi une opération et de recevoir plus d'évaluations de la douleur et d'interventions.

CONCLUSIONS : Tandis que les études récentes indiquent une douleur réduite chez les patients hospitalisés en pédiatrie, les présentes observations révèlent une fréquence élevée et continue de douleur sous-traitée. Les taux élevés de douleur liée aux interventions sont évitables, et il faudrait les cibler compte tenu de la sous-utilisation des stratégies de gestion de la douleur.

pain treatment thresholds (ie, the point when patients want something to relieve their pain) $(15,16)$. The aim of the present study was to more accurately capture pediatric inpatient pain prevalence and treatment adequacy by accounting for pain treatment thresholds, an approach recently recommended to be more consistent with the subjective nature of pain (17). This approach was taken because children and their parents have previously reported considerable variability in pain treatment thresholds following major and minor surgery, reflecting individual preferences for pain treatment not explained by time elapsed since surgery, or child age or sex $(15,16)$.

Our primary objective was to obtain a cross-section of pain experiences among hospitalized children. Using patient or parent interviews and medical chart review of the previous $24 \mathrm{~h}$ of hospitalization, the present study examined: the prevalence of pain in pediatric inpatients; major sources of pain; perceptions and documentation of

${ }^{1}$ Department of Psychology and Neuroscience, Dalhousie University; ${ }^{2} \mathrm{IWK}$ Health Centre; ${ }^{3}$ Department of Pediatrics, Dalhousie University;

Halifax, Nova Scotia; ${ }^{4}$ School of Nursing, University of Ottawa, Ottawa, Ontario; Departments of ${ }^{5}$ Nursing, ${ }^{6}$ Psychiatry and ${ }^{7}$ Anesthesia,

Dalhousie University, Halifax, Nova Scotia

Correspondence: Ms Kathryn A Birnie, Centre for Pediatric Pain Research (West), K8536 (8th floor Children's site), IWK Health Centre, 5850/5980 University Avenue, Halifax, Nova Scotia B3K 6R8. Telephone 902-470-6906, fax 902-470-7118, e-mail kbirnie@dal.ca 
pharmacological and nonpharmacological pain interventions; pain assessment documentation; relationships between patient characteristics and pain prevalence, assessment and management; and demographic and medical variables associated with clinically significant pain, as determined using personal pain treatment thresholds.

\section{METHODS}

\section{Participants}

Potential participants included pediatric inpatients or their parent(s) on four units (pediatric intensive care, general medical, surgical and oncology/nephrology) at the IWK Health Centre (Halifax, Nova Scotia) on four nonconsecutive study days. The IWK Health Centre is a 248-bed teaching institution that provides primary, secondary and tertiary care to women, children and families in the Maritime provinces. Neonatal intensive care, emergency, psychiatric and day treatment units were excluded. Participants were excluded if they were non-Englishspeaking, the patient required isolation, participation was deemed to be inappropriate by nurses (ie, the patient was too ill) or the patient had previously participated in the study.

\section{Procedure}

The study was conducted on four separate week days approximately 6.5 weeks apart. Approximately equal proportions of the sample were recruited on each day. Parents or patients $\geq 16$ years of age provided informed consent. Assent was also provided by younger patients when capacity was deemed appropriate. Up to three attempts were made to contact families throughout a $9 \mathrm{~h}$ to $10 \mathrm{~h}$ period each study day. The study was approved by the IWK Research Ethics Board.

\section{Interview}

The interview was developed from previous studies of pediatric inpatient pain $(1,3,4)$ and asked about the patient's pain experience during the previous $24 \mathrm{~h}$, including pain intensity, pain treatment threshold, main sources of pain, whether any help was given for the pain (both pharmacological and nonpharmacological interventions) and the identity of who had provided that help. Parents were interviewed when the patient was either $<5$ years of age or had an estimated verbal mental age $<5$ years, given that children $\geq 5$ years are considered to be able to reliably report on their own pain (18). Parents were also interviewed if the patient was unable to communicate verbally (eg, sedated), sleeping or deferred reporting to their parents. Interviews lasted approximately $10 \mathrm{~min}$ to $15 \mathrm{~min}$ and occurred in patient rooms or private family rooms available on each unit. The interview was piloted with three families before the first study day. Twelve trained research assistants (11 women) with undergraduate or graduate degrees in psychology conducted the interviews.

Pain intensity: Patients and parents used the Faces Pain ScaleRevised (FPS-R) (18) to rate patient's current, worst and usual pain during the previous $24 \mathrm{~h}$ of hospitalization. The FPS-R is comprised of six faces depicting 'no pain' (neutral face) to 'most pain possible' (18) and is the most psychometrically sound measure for self-reported pain in children as young as four years of age (19). The FPS-R was also used to rate the patient's pain treatment threshold using the following question: "Point to the face that shows how much pain or hurt you would be okay with before getting help from an adult for your pain". This question is based on previous assessments of children's pain treatment threshold $(15,16)$ and focuses on determining when children desire any type of intervention for pain that they feel unable to manage independently (ie, pharmacological or nonpharmacological). Assessing pain treatment thresholds using the same single-item intensity scale as used for pain assessment efficiently provides information on perceived treatment adequacy, while also accommodating the highly individualized use of pain rating scales (17).

Clinically significant pain: Ratings for current, worst and usual pain were compared with each patient's pain treatment threshold. Pain was considered to be clinically significant if rated at a higher intensity than the patient's own pain treatment threshold (17).
TABLE 1

Source of information and demographics for 107 pediatric
inpatients

\begin{tabular}{|c|c|}
\hline \multicolumn{2}{|l|}{ Source of information on patient pain } \\
\hline Patient self-report & $31(29)$ \\
\hline Mother & $59(55)$ \\
\hline Father & $14(13)$ \\
\hline Other (eg, foster parent, grandparent) & $3(3)$ \\
\hline \multicolumn{2}{|l|}{ Patient characteristics } \\
\hline Male sex & $56(52)$ \\
\hline Age, years, mean \pm SD (range) & $7.59 \pm 6.01(0.06-18.93)$ \\
\hline Weight, kg, mean \pm SD & $29.68 \pm 22.52$ \\
\hline \multicolumn{2}{|l|}{ Patient medical demographics } \\
\hline $\begin{array}{l}\text { Days hospitalized before study day, } \\
\text { median (range) }\end{array}$ & $4(<1-169)$ \\
\hline \multicolumn{2}{|l|}{ Admitting diagnosis } \\
\hline Chronic & $46(43)$ \\
\hline Acute & $61(57)$ \\
\hline $\begin{array}{l}\text { Patients undergoing surgery in previous } \\
24 \mathrm{~h}\end{array}$ & $9(8)$ \\
\hline $\begin{array}{l}\text { Patients undergoing invasive procedures } \\
\text { in previous } 24 \mathrm{~h}\end{array}$ & $33(31)$ \\
\hline $\begin{array}{l}\text { Invasive procedures (if }>0 \text { ), median } \\
\text { (range) }\end{array}$ & $1(1-8)$ \\
\hline $\begin{array}{l}\text { Patients undergoing minimally invasive } \\
\text { procedures in previous } 24 \mathrm{~h}\end{array}$ & $49(46)$ \\
\hline $\begin{array}{l}\text { Minimally invasive procedures (if }>0 \text { ), } \\
\text { median (range) }\end{array}$ & $1(1-5)$ \\
\hline
\end{tabular}

Data presented as $n$ (\%) unless otherwise specified

Pain source and help received for pain: Patients or parents indicated the perceived source of current, worst or usual pain, respectively, and location was marked on a body map (20). They were asked about pharmacological interventions and nonpharmacological caregiver responses (ie, parents and health care providers) (21), whether these impacted pain and who had provided the most help.

\section{Medical chart review}

Demographic and medical variables for the study period are reported in Table 1 and were abstracted from a standardized $24 \mathrm{~h}$ period in the medical chart. Information on pain assessment and management was taken from standardized admission, assessment/intervention and vital signs forms in the medical chart. Chronic admitting diagnoses were defined as conditions of long duration (ie, $>3$ months) and generally slow progression that require ongoing health care management over time (22), or a new diagnosis of conditions likely to meet these criteria. All other admitting diagnoses were categorized as acute. Invasive procedures included skin breaking and other invasive procedures (eg, intravenous insertion, lumbar puncture). Minimally invasive procedures included all other nonsurgical procedures not categorized as 'invasive' (eg, ultrasound, dressing change).

\section{Statistical analyses}

Descriptive statistics and/or percentages were used for prevalence, major sources and location of pain, pain assessments and help received. Pearson's product-moment correlations, independentsamples $t$ tests and $\chi^{2}$ tests compared patient characteristics and pain intensity, assessment and management. Independent-samples $t$ tests and $\chi^{2}$ tests compared patients with clinically significant usual pain to those with usual pain not reaching clinical significance.

\section{Participants}

\section{RESULTS}

Sources of information about the patient's pain experience and patient demographics are reported in Table 1 . Interviews report the pain experiences of 107 inpatients (56 male) three weeks to 18 years of age 
TABLE 2

Prevalence, major sources and location of current, worst and usual pain

\begin{tabular}{|c|c|c|c|c|c|c|}
\hline & \multicolumn{2}{|c|}{ Current } & \multicolumn{2}{|c|}{ Worst } & \multicolumn{2}{|c|}{ Usual } \\
\hline & $n(\%)$ & Mean \pm SD & $n(\%)$ & Mean \pm SD & $n(\%)$ & Mean \pm SD \\
\hline \multicolumn{7}{|l|}{ Prevalence of pain } \\
\hline Any pain $(>0 / 10)$ & $50(47)$ & & $100(93)$ & & $77(72)$ & \\
\hline Below clinically significant pain & $42(39)$ & $3.02 \pm 1.66$ & $34(32)$ & $5.18 \pm 2.52$ & $51(48)$ & $3.49 \pm 1.83$ \\
\hline \multicolumn{7}{|l|}{ Sources of any pain $(>0 / 10)$} \\
\hline Disease-related pain (eg, Crohn disease) & $21(42)$ & & $29(29)$ & & $33(43)$ & \\
\hline Everyday discomfort (eg, teething, hunger) & $2(4)$ & & $8(8)$ & & $9(12)$ & \\
\hline Don't know/unsure & $3(6)$ & & $7(7)$ & & $3(4)$ & \\
\hline \multicolumn{7}{|l|}{ Location of any pain $(>0 / 10)$} \\
\hline Abdomen/groin & $20(40)$ & & $36(36)$ & & $33(43)$ & \\
\hline Legs/feet & $8(19)$ & & $10(10)$ & & $8(10)$ & \\
\hline Chest & $7(14)$ & & $12(12)$ & & $10(13)$ & \\
\hline Arms/hands & $1(2)$ & & $17(17)$ & & $2(3)$ & \\
\hline Spine/upper back & $1(2)$ & & $2(2)$ & & $2(3)$ & \\
\hline Multiple locations & $3(6)$ & & $3(3)$ & & $4(5)$ & \\
\hline No location (ie, "emotional pain") & $0(0)$ & & $0(0)$ & & $1(1)$ & \\
\hline
\end{tabular}

${ }^{*}$ Pain above each patient's personal pain treatment threshold was classified as clinically significant pain (17). Mean ( \pm SD) patient pain treatment threshold was $4.69 \pm 2.52$; thus, the cut-off for determining clinical significance varied among children

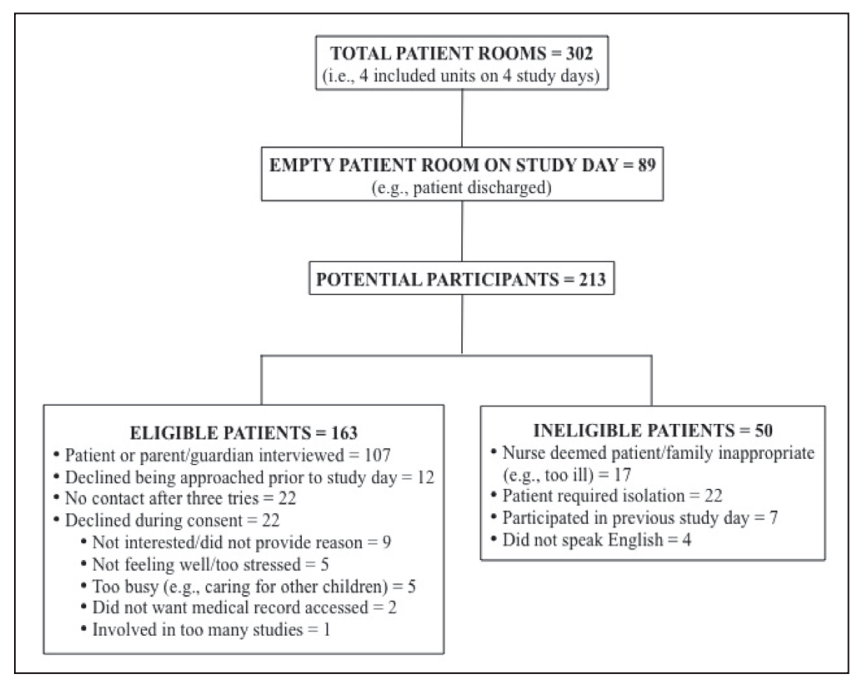

Figure 1) Study enrollment, participation rate and reasons for patient exclusion

(mean $[ \pm \mathrm{SD}]$ age $7.59 \pm 6.01$ years). Forty-seven patients $(44 \%)$ were $\leq 5$ years of age. Seventy-six parent and 31 patient interviews captured the 107 inpatient pain experiences, reflecting a study participation rate of $66 \%$. Participation rates for the four inpatient units ranged from $47 \%$ to $82 \%$, with the lowest rate on the oncology/nephrology unit. Participant enrollment and exclusion is summarized in Figure 1.

There were no differences in patient sex, admitting diagnosis (acute versus chronic), current pain intensity, hospital unit, number of surgeries or other medical procedures in the previous $24 \mathrm{~h}$ of hospitalization based on whether a parent or the child was interviewed. Interviewed patients were older than patients whose parents were interviewed (mean age $12.48 \pm 3.60$ years versus $5.56 \pm 5.56$ years; $t(105)=7.55 ; \mathrm{P}<0.01)$.

\section{Prevalence of pain}

Prevalence of any pain and clinically significant pain are described in Table 2. Almost all patients $(\mathrm{n}=101[94 \%])$ experienced some pain
( $>0$ of 10). Highest rates of clinically significant pain were reported for worst pain $(n=66[62 \%])$, followed by usual pain $(n=26[24 \%])$ and current pain $(n=8[8 \%])$. The mean pain treatment threshold was $4.69 \pm 2.52$; thus, the cut-off for determining the presence of clinically significant pain varied among children.

Major sources and location of pain

Major sources and location of any current, worst and usual pain are summarized in Table 2. Current and worst pain were primarily from procedures, whereas usual pain was primarily disease-related. A greater percentage of worst pain was attributed to medical procedures or interventions. Frequent locations of pain were chest, legs/feet and face (usual pain), and arms/hands (worst pain). The most common area of all pain was the abdomen/groin.

\section{Help received for pain}

Primary providers of help: Interviews: Primary providers of help for any pain are presented in Table 3. Nurses were most frequently identified for current $(n=27[54 \%])$, worst $(n=50[50 \%])$ and usual $(n=45[58 \%])$ pain, followed by parent(s) (12\% to $27 \%$ ) and doctors ( $7 \%$ to $16 \%$ ). Other health care providers (eg, child life specialists) and family members/friends (eg, siblings) were identified less frequently $(<5 \%)$. Importantly, $8 \%$ to $12 \%$ of interviews indicated that no one had helped with the patient's pain.

Medical charts: Pain was addressed in physician notes for less than onehalf of patients $(n=44[41 \%])$ with fewer noting a pain treatment plan $(n=20[19 \%])$. Pain was noted in physician notes for three $(38 \%)$ patients with clinically significant current pain, 27 (41\%) patients with clinically significant worst pain and $13(50 \%)$ of patients with clinically significant usual pain. Nine patients $(8 \%)$ had a consultation with the hospital's specialized pain management team. The profile of these patients was heterogeneous with regard to pain intensity ( 0 to 8 of 10), pain source, sex (five males), age (three to 17 years), admitting service and diagnosis (six acute) and length of hospitalization (one to 51 days).

Pharmacological interventions: Pharmacological interventions reported by patients and parents, as well as documented in medical 
TABLE 3

Primary provider of help for any ( $>0$ of 10 ) current, worst and usual pain

\begin{tabular}{lccc}
\hline Provider & $\begin{array}{c}\text { Current } \\
(\mathbf{n}=50)\end{array}$ & $\begin{array}{c}\text { Worst } \\
(\mathbf{n}=100)\end{array}$ & $\begin{array}{c}\text { Usual } \\
(\mathbf{n}=77)\end{array}$ \\
\hline Nurse & $27(54)$ & $50(50)$ & $45(58)$ \\
Parent(s) & $9(18)$ & $27(27)$ & $21(27)$ \\
Doctor & $8(16)$ & $8(8)$ & $5(7)$ \\
$\begin{array}{l}\text { Other health care provider } \\
\quad(\text { eg, child life specialist) }\end{array}$ & $0(0)$ & $4(4)$ & $0(0)$ \\
$\begin{array}{l}\text { Other family member/ } \\
\text { friend (eg, sibling) }\end{array}$ & $0(0)$ & $1(1)$ & $0(0)$ \\
No one & $6(12)$ & $10(10)$ & $6(8)$ \\
\hline
\end{tabular}

Data presented as $n(\%)$

charts, are reported in Table 4.

Interviews: Patients with any pain (>0 of 10$)$ reported receiving medication more frequently for current (88\%) versus usual (77\%) or worst (67\%) pain. When medication was given, approximately $90 \%$ reported it as having been at least 'a little helpful'.

Medical charts: While most patients $(n=94 ; 88 \%)$ had at least one pharmacological prescription for pain documented in their medical chart, fewer patients $(n=71 ; 66 \%)$ received a pharmacological intervention for pain. Acetaminophen and/or nonsteroidal anti-inflammatory drugs (NSAIDs) were most frequently administered, followed by opioids and adjuvants. Use of topical anesthetics was infrequent $(n=3)$. Of the $36(33 \%)$ patients who did not receive pharmacological intervention, none had clinically significant current pain, 11 (31\%) had clinically significant worst pain and seven $(19 \%)$ had clinically significant usual pain.

Caregiver responses and nonpharmacological interventions: Caregiver responses reported by patients and parents, as well as nonpharmacological interventions documented in medical charts, are reported in Table 4.

Interviews: All patients $(\mathrm{n}=101)$ who reported any pain in the previous $24 \mathrm{~h}$ of hospitalization reported some nonpharmacological caregiver responses. The five most common caregiver responses to children's pain included cognitive distraction, praise, reassurance, humour and empathy. Allowing the patient to choose how to minimize their pain (ie, control to child) and patient self-focused nonpharmacological coping (ie, distracting oneself) were less common. Criticizing the patient was uncommon $(5 \%)$.

Medical charts: Less than one-half of patients $(n=45$ [42\%]) had any nonpharmacological interventions documented in their medical chart. Cognitive distraction was reported with approximately onethird of patients, followed by physical strategies such as comfort positioning, heat/cold therapy, other (eg, cuddles with parents, rest) and commands to cope.

\section{Documented pain assessment}

Patients located in the pediatric intensive care unit $(n=8)$ for the $24 \mathrm{~h}$ period were excluded from the present analysis, given the different procedures and tools used for pain assessment and documentation. The remaining 99 patients had at least one documented pain assessment in the previous $24 \mathrm{~h}$. Excluding patients admitted/discharged during the $24 \mathrm{~h}$ period $(n=6)$, the majority $(n=84$ [90\%]) of patients had their pain assessed at least once per $12 \mathrm{~h}$ shift in accordance with hospital guidelines. In total, 399 pain assessments were recorded, with a mean of $4.03 \pm 3.06$ pain assessments (range one to 18 ) per patient. Of these documented pain assessments, 254 (64\%) did not note the pain assessment tool used, although $64(25 \%)$ of those without a noted pain assessment tool did report an intensity rating. Of the 145 pain assessments with a documented tool, behavioural assessment of pain $(n=79[54 \%])$ was most common, followed by a numerical rating scale $(n=49[34 \%])$, the FPS-R $(n=14[10 \%])$ or the Poker Chip Tool $(n=3[2 \%])$.
TABLE 4

Pharmacological and nonpharmacological intervention for current, worst and usual pain

Patient or parent report of phamacological intervention for any pain ( $>0$ of 10$)$

\begin{tabular}{lccc}
\hline & $\begin{array}{c}\text { Current } \\
(\mathbf{n = 5 0 )}\end{array}$ & $\begin{array}{c}\text { Worst } \\
(\mathbf{n = 1 0 0 )}\end{array}$ & $\begin{array}{c}\text { Usual } \\
(\mathbf{n = 7 7 )}\end{array}$ \\
\hline $\begin{array}{l}\text { Was the patient given medication for pain? } \\
\text { Yes }\end{array}$ & $44(88)$ & $67(67)$ & $59(77)$ \\
If yes, did the medication help? & & & \\
Yes, more than a little & $31(71)$ & $52(78)$ & $46(78)$ \\
A little & $8(18)$ & $8(12)$ & $7(12)$ \\
No & $5(11)$ & $5(8)$ & $4(7)$ \\
Don't know/unsure & $0(0)$ & $2(3)$ & $2(3)$
\end{tabular}

Pharmacological intervention in medical chart for all patients $(n=107)$

\begin{tabular}{lcc}
\hline & Prescribed & Received \\
\hline Acetaminophen and/or & $93(87)$ & $67(63)$ \\
$\quad$ NSAID & & \\
Opioid & $48(45)$ & $38(36)$ \\
Adjuvant* & $13(12)$ & $13(12)$ \\
Topical anesthetic & $10(9)$ & $3(3)$
\end{tabular}

Caregiver responses and nonpharmacological interventions

\begin{tabular}{|c|c|c|}
\hline & $\begin{array}{c}\text { Reported in } \\
\text { interviews for } \\
\text { patients with } \\
\text { any pain, } n=101^{\dagger}\end{array}$ & $\begin{array}{l}\text { Medical chart for } \\
\text { all patients, } n=107\end{array}$ \\
\hline Cognitive distraction & $93(94)$ & $36(34)$ \\
\hline Praise & $93(93)$ & $0(0)$ \\
\hline Reassurance & $88(88)$ & $0(0)$ \\
\hline Humour & $75(77)$ & $0(0)$ \\
\hline Empathy & $73(74)$ & $0(0)$ \\
\hline Apology & $68(67)$ & $0(0)$ \\
\hline Comfort positioning & $66(66)$ & $22(21)$ \\
\hline Information provision & $58(64)$ & $0(0)$ \\
\hline Commands to cope & $55(64)$ & $1(1)$ \\
\hline Massage & $50(50)$ & $0(0)$ \\
\hline $\begin{array}{l}\text { Skin-to-skin contact/ } \\
\text { cuddling }\end{array}$ & $48(48)$ & $10(9)$ \\
\hline Heat/cold therapy & $38(38)$ & $11(10)$ \\
\hline Control to child & $26(31)$ & $0(0)$ \\
\hline Criticism & $5(5)$ & $0(0)$ \\
\hline $\begin{array}{l}\text { Other (eg, rest/sleep, } \\
\text { stuffed animals, treats, } \\
\text { bath) }\end{array}$ & $14(14)$ & $1(1)$ \\
\hline \multicolumn{3}{|l|}{ Patient self-focused coping } \\
\hline Deep breathing & $38(48)$ & - \\
\hline Cognitive distraction & $31(42)$ & - \\
\hline Making coping statements & $29(37)$ & - \\
\hline Humour & $29(36)$ & - \\
\hline None & $0(0)$ & $62(58)$ \\
\hline \multicolumn{3}{|c|}{ Did the help from an adult help decrease the pain? ${ }^{\ddagger}$} \\
\hline Yes & $85(84)$ & - \\
\hline No & $11(11)$ & - \\
\hline Don't know/unsure & $4(4)$ & - \\
\hline
\end{tabular}

Data presented as $n$ (\%). *Adjuvants included amitriptyline, gabapentin, ketamine, lidocaine, pregabalin and nortriptyline; ${ }^{\dagger}$ Percentages of patients receiving nonpharmacological interventions as reported during interviews were not always based on the entire sample of patients with pain $(n=101)$ because some strategies were not applicable given child age (eg, infant) or medical status (eg, sedated); $¥$ This question was missed for one patient. NSAID Nonsteroidal anti-inflammatory drug 
TABLE 5

Patient demographic and medical variables associated with clinically significant usual pain

\begin{tabular}{|c|c|c|c|c|c|c|c|}
\hline Demographic and medical variables & \multicolumn{2}{|c|}{$\begin{array}{l}\text { Clinically significant pain } \\
\qquad(n=26)\end{array}$} & \multicolumn{2}{|c|}{$\begin{array}{c}\text { Below clinically } \\
\text { significant pain }(n=81)\end{array}$} & \multicolumn{3}{|c|}{ Test of group differences } \\
\hline Patient sex (\% male) & $15(58)$ & & $41(51)$ & & & 0.395 & 0.53 \\
\hline Patient age, years & & $7.37 \pm 5.74$ & & $7.66 \pm 6.13$ & 0.220 & & 0.83 \\
\hline Days hospitalized & & $7.46 \pm 11.04$ & & $12.36 \pm 24.69$ & 0.978 & & 0.33 \\
\hline Undergone invasive procedure in previous $24 \mathrm{~h}$ & $9(35)$ & & $24(30)$ & & & 0.229 & 0.63 \\
\hline Undergone surgical procedure in previous $24 \mathrm{~h}$ & $5(19)$ & & $4(5)$ & & & 5.22 & 0.02 \\
\hline Received pharmacological intervention & $25(96)$ & & $46(57)$ & & & 13.66 & $<0.01$ \\
\hline Opioids & $13(50)$ & & $25(31)$ & & & 3.15 & 0.08 \\
\hline Nonsteroidal anti-inflammatory drugs & $23(88)$ & & $44(54)$ & & & 9.80 & $<0.01$ \\
\hline
\end{tabular}

Patient characteristics and pain

Pain intensity: Older patients reported higher current $(\mathrm{r}=0.277$; $\mathrm{P}<0.01)$, but not worst $(\mathrm{r}=-0.111 ; \mathrm{P}=0.25)$ or usual $(\mathrm{r}=0.178 ; \mathrm{P}=0.07)$ pain. Number of minimally invasive procedures was positively correlated with worst $(\mathrm{r}=0.234 ; \mathrm{P}<0.05)$, but not current $(\mathrm{r}=0.096 ; \mathrm{P}=0.33)$ or usual $(\mathrm{r}=0.042 ; \mathrm{P}=0.67)$ pain. Patient sex, admitting diagnosis (acute versus chronic), number of invasive procedures ( 0 versus $\geq 1$ ), whether the patient had undergone surgery and number of days hospitalized were unrelated to current, worst or usual pain.

Pain treatment thresholds: Older patients reported higher pain treatment thresholds $(\mathrm{r}=0.284 ; \mathrm{P}<0.01)$. Patients who had undergone at least one invasive procedure $(t=3.00 ; \mathrm{P}<0.01)$ or surgery $(t=1.99$; $\mathrm{P}<0.05)$ had significantly lower pain treatment thresholds. Patient sex, admitting diagnosis (acute versus chronic), number of minimally invasive procedures and number of days hospitalized were unrelated to reported pain treatment thresholds.

Pain assessment: Older patients had more documented pain assessments $(r=0.206 ; \mathrm{P}<0.05)$. Patient sex, admitting diagnosis (acute versus chronic), number of invasive ( 0 versus $\geq 1$ ) and minimally invasive procedures, whether the patient had undergone surgery and number of days hospitalized were unrelated to the number of documented pain assessments.

Pain management: Patients with documented nonpharmacological intervention for pain were hospitalized for fewer days $(t=-2.39$; $\mathrm{P}<0.05)$ and had more pain assessments $(t=-5.61 ; \mathrm{P}<0.01)$. Patient age, sex, admitting diagnosis (acute versus chronic), number of invasive ( 0 versus $\geq 1$ ) and minimally invasive procedures, and whether the patient had undergone surgery were unrelated to having documented nonpharmacological pain management. Patients who had received any pharmacological pain intervention were more likely to have an acute admitting diagnosis $\left(\chi^{2}=5.21 ; \mathrm{P}<0.05\right)$, had undergone a greater number of minimally invasive procedures $(t=-0.324 ; \mathrm{P}<0.01)$ and had more documented pain assessments $(t=-3.50 ; \mathrm{P}<0.01)$. Patient age, sex, number of days hospitalized, number of invasive ( 0 versus $\geq 1$ ) procedures and whether the patient had undergone surgery were unrelated to documented pharmacological pain interventions.

Patients who received opioids were older $(t=2.95 ; \mathrm{P}<0.01)$, had been hospitalized for fewer days $(t=-2.39 ; \mathrm{P}<0.05)$, had more documented pain assessments $(t=4.22 ; \mathrm{P}<0.01)$, had undergone a greater number of minimally invasive procedures $(t=2.33 ; \mathrm{P}<0.05)$ and were more likely to have undergone surgery $\left(\chi^{2}=12.22 ; \mathrm{P}<0.01\right)$. Patients who received acetaminophen and/or NSAIDs were more likely to have an acute reason for hospitalization $\left(\chi^{2}=7.54 ; \mathrm{P}<0.01\right)$ and had more documented pain assessments $(t=3.76 ; \mathrm{P}<0.01)$. Patients who received adjuvants were older $(t=2.17 ; \mathrm{P}<0.05)$ and were more likely to have undergone surgery $\left(\chi^{2}=27.36 ; \mathrm{P}<0.01\right)$. No other significant relationships were noted between patient characteristics and pain management.

Patients with clinically significant usual pain

Participant demographics and medical variables associated with clinically significant usual pain are presented in Table 5. Patients with clinically significant usual pain were more likely to have undergone surgery, received pharmacological intervention (particularly acetaminophen and/or NSAIDs and adjuvants), documented nonpharmacological interventions and more documented pain assessments. No differences were noted in patient age, sex, number of days hospitalized, number of minimally invasive procedures, the likelihood of having undergone at least one invasive procedure or whether opioids were received.

\section{DISCUSSION}

Almost all patients experienced pain in the previous $24 \mathrm{~h}$ of hospitalization. Our study is the first to account for the level of pain at which patients desire intervention (ie, pain treatment thresholds) when interpreting the prevalence of clinically significant pain among hospitalized children. Previous studies have used standardized cut-offs of moderate to severe pain, omitting lower-intensity pain in prevalence rates $(1,3,4,7)$. However, observed pain treatment thresholds in the present study indicate that low-intensity pain is still considered to be clinically significant to some patients. This approach more accurately characterizes rates of undermanaged pain and is more consistent with the subjectivity of pain $(17,23)$. Using this approach, the prevalence of clinically significant pain ranged from $8 \%$ (current pain) to $62 \%$ (worst pain), with $24 \%$ of patients with clinically significant usual pain.

While recent studies have reported decreasing pain prevalence among hospitalized children (5,10-12), our findings suggest prevalence rates closer to studies five to 20 years ago $(1,2,4,9)$. The validity of recent studies is problematic given their reliance on medical chart review alone to inform the prevalence of pain $(5,10,11)$. Coupled with health professionals' tendency to underestimate children's pain (24), chart reviews may underestimate children's pain prevalence, given the large proportion of patients with no documented pain assessment, reported to be $>30 \%$ (11).

Findings suggest that younger inpatients are particularly at risk for poorer pain assessment and management. Positively, children with clinically significant usual pain received closer monitoring, as evidenced by more pain assessments and pharmacological and nonpharmacological interventions, than those with pain below their pain treatment 
threshold. However, by reporting usual pain above their pain treatment threshold, these children were indicating that throughout the past $24 \mathrm{~h}$, they typically experienced pain for which they desired further intervention. Importantly, this group was also more likely to have undergone surgery in the previous $24 \mathrm{~h}$, perhaps indicating that some patients continue to receive inadequate postoperative pain management. This is consistent with research demonstrating that surgical pediatric patients are more likely to experience pain than medical patients (7). On the one hand, having undergone surgery may cue closer monitoring of pain, while on the other hand, it may lead to the assumption that moderate to severe pain is an unavoidable consequence of surgery (25).

Overall, $42 \%$ to $56 \%$ of reported pain was attributed to medical procedures. This was more frequently noted for worst pain, suggesting that pain associated with procedures and intervention is often worse than the underlying reason for hospitalization. This is particularly concerning given that this pain can be minimized with effective intervention $(13,14)$. Findings also suggested the underuse of topical anesthetics to preemptively manage procedure-related pain.

Although $94 \%$ of patients had physician orders for pain management, only two-thirds received any pharmacological intervention. When given, $90 \%$ of patients reported medications were at least 'a little helpful' in reducing pain, suggesting that pharmacological treatments can be effective when used. A minority of those not receiving pharmacological intervention reported clinically significant pain. Some suggest that there is a need to balance pain intensity with oversedation and possible risks associated with pharmacological treatment (26). Additional research is needed to better understand potential factors (eg, health professional or patient characteristics) that contribute to the decision of whether prescribed pharmacological interventions are actually administered. Generally, patients receiving pharmacological intervention were likely to have more frequently documented pain assessments. However, the usefulness of the documentation was limited because only one-third indicated the pain measure used and only onequarter included a pain intensity rating, similar to previous research (11). Encouragingly, all patients had at least one documented pain assessment in the previous $24 \mathrm{~h}$ of hospitalization with $90 \%$ assessed in accordance with hospital guidelines (at least once per $12 \mathrm{~h} \mathrm{shift).}$

Consistent with previous research (1), nurses were noted to be the primary provider of care in $\geq 50 \%$ of interviews. Of concern was the $8 \%$ to $12 \%$ of interviews that reported no one had helped with the patient's current, worst or usual pain. Future research is needed to explore whether this is a result of real inadequate pain management or is a lack of communication between health professionals and patients and families about what efforts are being taken to manage pain. Physicians noted pain in medical chart notes at a much higher rate than in previous research (7), although less than one-half of children reporting clinically significant pain had pain noted by physicians. The specialized acute pain service was consulted in $8 \%$ of patients, with no clear referral pattern. Greater utilization of the specialized acute pain service may be an area for consideration, because a lower prevalence of pain was reported in a hospital at which $42 \%$ of patients received consultation from a specialized pain service (7).

Importantly, after nurses, parents were identified as the primary provider of help for pain. Parents play a part in the nonpharmacological management of children's pain and may be underutilized (27). Caregiver responses to children's pain reported high rates of nonpharmacological strategies, including helpful (eg, cognitive distraction) (28) and unhelpful (eg, reassurance) (29) pain reduction strategies. Nonpharmacological strategies were reported at a much higher rate than previous research (4), likely due to the yes/no question format or parents' tendency to overestimate their behaviours during children's pain (21). However, this afforded valuable information given the limited documentation of nonpharmacological strategies in medical charts, for which there is no standardized recording method. Of note, we would not expect all types of caregiver responses assessed in the present study to be considered formalized nonpharmacological interventions and relevant for documentation in the medical chart (eg, praise, criticism). However, despite systematic reviews supporting the effectiveness of nonpharmacological interventions for pediatric pain $(28,30,31)$, observational evidence is required to determine underreporting or underutilization (32).

Surprisingly, despite increased awareness and improvements in pediatric pain assessment and management $(13,14)$, rates of clinically significant inpatient pain remain high. Possible explanations are the increased medical complexity of hospitalized children (33), or a lack of knowledge, lack of time or institutional/unit culture regarding pain assessment and management (34). Chorney et al (25) suggested that, to change clinical practice, clinically significant pain should be treated as any other adverse event. Local (35) and global (36) initiatives support institutional improvement of pain management for hospitalized children. Studies, such as the current analysis, can be used to evaluate the impact of knowledge translation initiatives to improve painrelated patient care (10) and to facilitate audits. Additionally, many questions are raised by our novel application of pain treatment thresholds to identify levels of clinically significant pain (17), as well as the lower pain treatment thresholds reported for younger patients and those who had undergone invasive or surgical procedures. Further investigation is needed to understand how patients and parents select pain treatment thresholds, whether these are realistic given medical circumstances, and how clinicians can utilize these reports to inform patient care.

Although family report of pain experiences is an improvement over previous work, the proportion of parent proxy report (71\%) is a limitation given their tendency to underestimate children's pain (37). The present study was also limited by its participation rate, although representative samples were obtained from three of four units where $65 \%$ to $82 \%$ of eligible families participated. Although $<2 \%$ of potential participants were excluded for being non-English-speaking, this group of children may be particularly vulnerable to inadequate pain assessment and management. Additionally, pain experiences of particularly ill children may be underrepresented given their potential exclusion by clinician decision.

\section{CONCLUSION}

Unfortunately, these findings continue to highlight the lack of adequate pain intervention for most hospitalized children. Pain treatment thresholds suggest that, while some pain is tolerable to most patients without intervention, others desire further intervention for low-intensity pain. In particular, the high rates of procedure-related pain should be considered preventable and targeted for improvement given the observed underutilization of pharmacological and nonpharmacological strategies. Future research should explore which aspects (ie, assessment, nonpharmacological/pharmacological interventions) and provider of care have the greatest impact for minimizing pain, as well as investigating observed relationships between patient characteristics and pain prevalence, assessment and management practices. With continued effort and attention, undertreated pain can be avoided.

ACKNOWLEDGEMENTS: The authors thank Katelynn Boerner, Aimee Coulombe, Aimee Dort, Samantha Eisen, Bryanne Harris, Rebecca MacNevin, Melanie Noel, Jennifer Parker, Mark Petter, Laura Slauenwhite and Leah Wofsy, research assistants who interviewed patients and parents, and Adele Gouthro, a research assistant who conducted the medical chart reviews. The authors also thank the hospital administration, unit managers and clinical nurse specialists for supporting the present study, as well as the families who participated.

FUNDING: The present study was supported by a Category A Grant from the IWK Health Centre and funding from the Canadian Institutes of Health Research held by Dr Christine Chambers and Dr Patrick McGrath. Kathryn Birnie is a Vanier Canada Graduate Scholar and was supported by the Canadian Institutes of Health Research Team in Children's Pain. Dr Patrick McGrath and Dr Christine Chambers are supported by Canada Research Chairs. 


\section{REFERENCES}

1. Cummings EA, Reid GJ, Finley GA, McGrath PJ, Ritchie JA. Prevalence and source of pain in pediatric inpatients. Pain 1996;68:25-31.

2. Harrison A. Comparing nurses' and patients' pain evaluations: A study of hospitalized patients in Kuwait. Soc Sci Med 1993;36:683-92.

3. Johnston CC, Abbott FV, Gray-Donald K, Jeans ME. A survey of pain in hospitalized patients aged 4-14 years. Clin J Pain 1992;8:154-63.

4. Ellis JA, O'Connor BV, Cappelli M, Goodman JT, Blouin R, Reid CW. Pain in hospitalized pediatric patients: How are we doing? Clin J Pain 2002;18:262-9.

5. Groenewald CB, Rabbitts JA, Schroeder DR, Harrison TE. Prevalence of moderate-severe pain in hospitalized children. Paediatr Anaesth 2012;22:661-8.

6. Karling M, Renström M, Ljungman G. Acute and postoperative pain in children: A Swedish nationwide survey. Acta Paediatr 2002;91:660-6.

7. Kozlowski LJ, Kost-Byerly S, Colantuoni E, et al. Pain prevalence, intensity, assessment and management in a hospitalized pediatric population. Pain Manag Nurs 2012: In press.

8. Melotti RM, Samolsky-Dekel BG, Ricchi E, et al. Pain prevalence and predictors among inpatients in a major Italian teaching hospital. A baseline survey towards a pain free hospital. Eur J Pain 2005;9:485-95.

9. Taylor EM, Boyer K, Campbell FA. Pain in hospitalized children: A prospective cross-sectional survey of pain prevalence, intensity, assessment and management in a Canadian pediatric teaching hospital. Pain Res Manage 2008;13:25-32.

10. Zhu LM, Stinson J, Palozzi L, et al. Improvements in pain outcomes in a Canadian pediatric teaching hospital following implementation of a multifaceted knowledge translation initiative. Pain Res Manag 2012;17:173-9.

11. Stevens BJ, Harrison D, Rashotte J, et al. Pain assessment and intensity in hospitalized children in Canada. J Pain 2012;13:857-65.

12. Stevens BJ, Abbott LK, Yamada J, et al. Epidemiology and management of painful procedures in children in Canadian hospitals. CMAJ 2011;183:E403-10.

13. Berde CB, Sethna NF. Analgesics for the treatment of pain in children. N Engl J Med 2002;347:1094-103.

14. Srouji R, Ratnapalan S, Schneeweiss S. Pain in children: Assessment and nonpharmacological management. Int J Pediatr 2010;2010:1-10.

15. Demyttenaere S, Finley GA, Johnston CC, McGrath PJ. Pain treatment thresholds in children after major surgery. Clin J Pain 2001;17:173-7.

16. Gauthier JC, Finley GA, McGrath PJ. Children's self-report of postoperative pain intensity and treatment threshold: Determining the adequacy of medication. Clin J Pain 1998;14:116-20.

17. Birnie KA, McGrath PJ, Chambers CT. When does pain matter? Acknowledging the subjectivity of clinical significance. Pain 2012;153:2311-4.

18. Hicks CL, von Baeyer CL, Spafford PA, van Korlaar I, Goodenough B. The Faces Pain Scale-Revised: Toward a common metric in pediatric pain measurement. Pain 2001;93:173-83.
19. Stinson JN, Kavanagh T, Yamada J, Gill N, Stevens B. Systematic review of the psychometric properties, interpretability and feasibility of self-report pain intensity measures for use in clinical trials in children and adolescents. Pain 2006;125:143-57.

20. Reid GJ, Gilbert CA, McGrath PJ. The Pain Coping Questionnaire: Preliminary validation. Pain 1998;76:83-96.

21. Cohen LL, Manimala R, Blount RL. Easier said than done: What parents say they do and what they do during children's immunizations. Child Health Care 2000;29:79-86.

22. Pruitt S, Annandale S, Epping-Jordan J, et al. Innovative Care for Chronic Conditions: Building Blocks for Action. World Health Organization. 2002.

23. Voepel-Lewis T, Burke CN, Jeffreys N, Malviya S, Tait AR. Do 0-10 numeric rating scores translate into clinically meaningful pain measures for children? Anesth Analg 2011;112:415-21.

24. Singer AJ, Gulla J, Thode Jr HC. Parents and practitioners are poor judges of young children's pain severity. Acad Emerg Med 2002;9:609-12.

25. Chorney JM, McGrath P, Finley GA. Pain as the neglected adverse event. CMAJ 2010;182:732.

26. Greco C, Berde C. Pain management for the hospitalized pediatric patient. Pediatr Clin North Am 2005;52:995-1027.

27. Twycross A, Collis S. How well is acute pain in children managed? A snapshot in one English hospital. Pain Manag Nurs 2013;14:e204-15.

28. Uman LS, Chambers CT, McGrath PJ, Kisely S. Psychological interventions for needle-related procedural pain and distress in children and adolescents. Cochrane Database Syst Rev 2006;4:CD005179.

29. Taylor C, Sellick K, Greenwood K. The influence of adult behaviors on child coping during venipuncture: A sequential analysis. Res Nurs Health 2011;34:116-31.

30. Pillai Riddell RR, Racine NM, Turcotte K, et al. Non-pharmacological management of infant and young child procedural pain. Cochrane Database Syst Rev 2011;10:CD006275.

31. Stinson J, Yamada J, Dickson A, Lamba J, Stevens B. Review of systematic reviews on acute procedural pain in children in the hospital setting. Pain Res Manage 2008;13:51-7.

32. Twycross A. Children's nurses' post-operative pain management practices: An observational study. Int J Nurs Stud 2007;44:869-81.

33. Simon TD, Berry J, Feudtner C, et al. Children with complex chronic conditions in inpatient hospital setting in the United States. Pediatrics 2010;126:647-55.

34. Meijers JM, Janssen MA, Cummings GG, Wallin L, Estabrooks CA, Halfens R. Assessing the relationships between contextual factors and research utilization in nursing: Systematic literature review. J Adv Nurs 2006;55:622-35.

35. Schechter NL. From the Ouchless Place to Comfort Central: The evolution of a concept. Pediatrics 2008;122(Suppl 3):S154-60.

36. Schechter NL, Finley GA, Bright NS, Laycock M, Forgeron P. ChildKind: A global initiative to reduce pain in children. Pediatr Pain Lett 2010;12:26-30.

37. Chambers CT, Reid GJ, Craig KD, McGrath PJ, Finley GA. Agreement between child and parent reports of pain. Clin J Pain 1998; $14: 336-42$. 


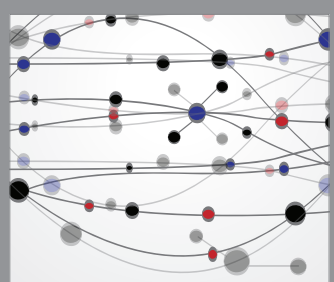

The Scientific World Journal
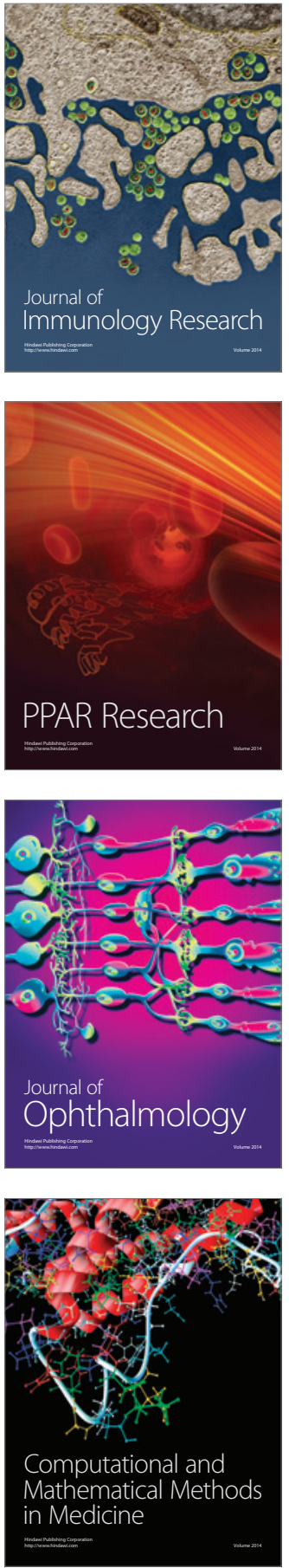

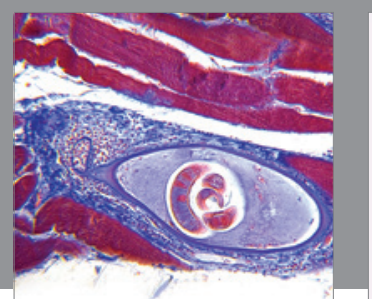

Gastroenterology Research and Practice

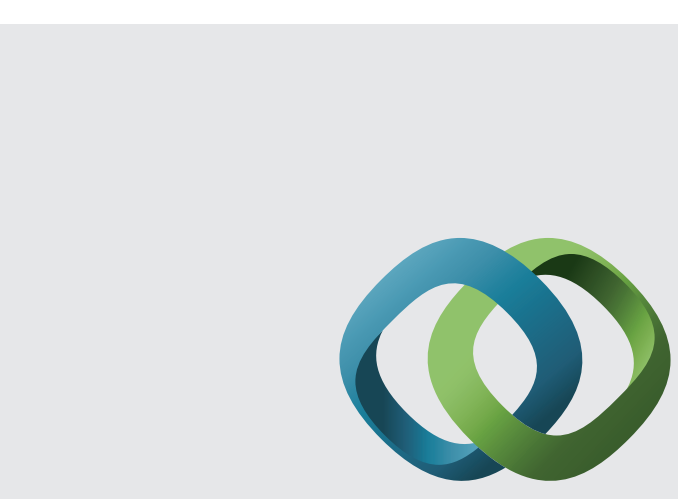

\section{Hindawi}

Submit your manuscripts at

http://www.hindawi.com
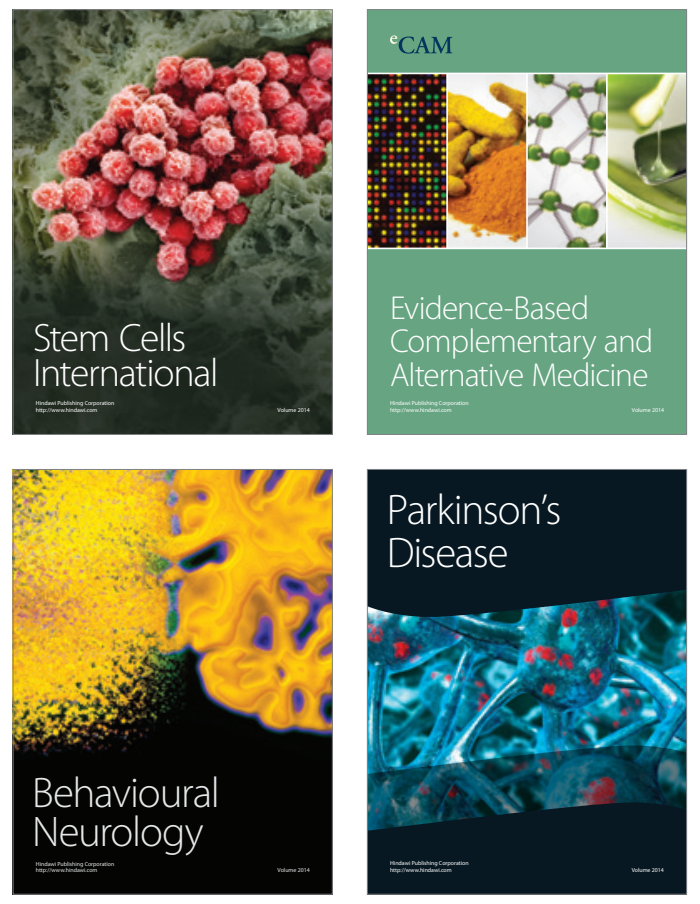
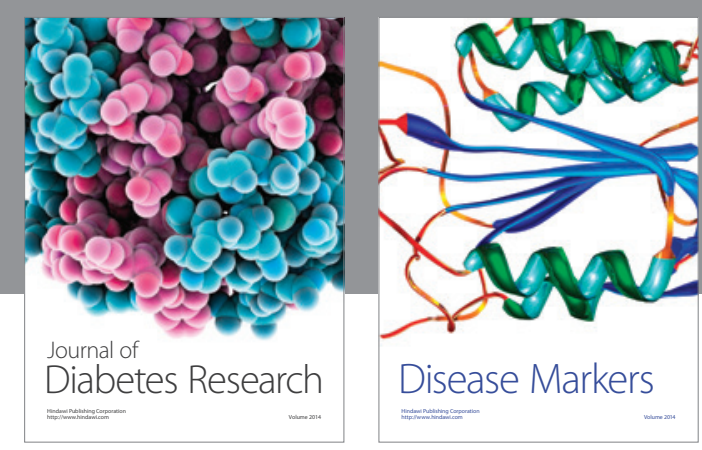

Disease Markers
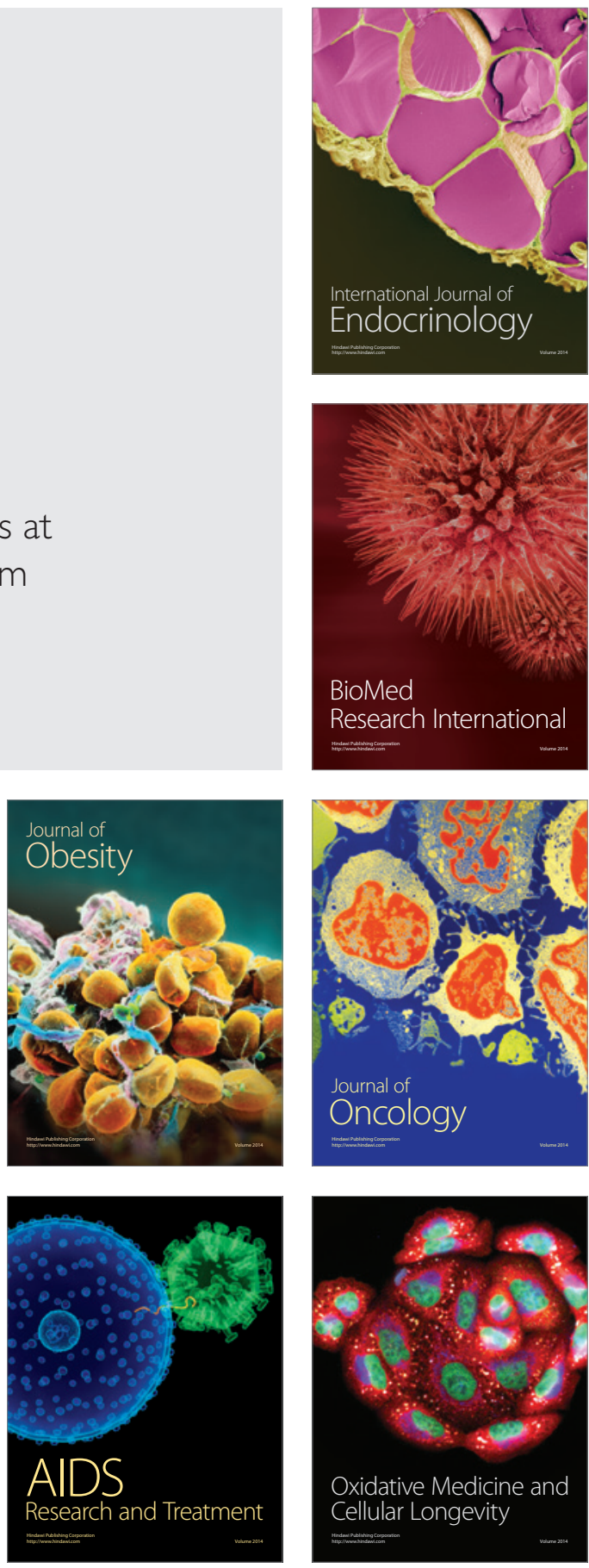